\title{
¿HUBO PROPAGANDA FATIMÍ ENTRE LOS KUTĀMA ANDALUSÍES? ${ }^{1}$
}

\author{
MARIBEL FIERRO \\ CSIC, Madrid
}

En la segunda mitad del s. III/IX hay indicios de actividad propagandística isma'ilí en al-Andalus ${ }^{2}$, actividad que culminaría con la llegada de dos misioneros fatimíes al territorio controlado por Ibn Hafșūn con objeto de recompensarle por su reconocimiento del califato fatimí ${ }^{3}$. No está claro hasta qué punto se pueda considerar un misionero fatimí al asceta conocido como Abū 'Alī al-Sarrāŷ. Tenemos noticia de este personaje en el año 285/898, cuando actúa como intermediario para los intentos de alianza antiomeya entre los Banū Qasī de Aragón y 'Umar b. Hafșūn. Posteriormente, en el año 288/900-1 lo volvemos a encontrar como figura crucial en el asunto de Ibn al-Qitt, un miembro de la familia omeya que encabezó una rebelión contra el emir "Abd Allāh (r. 275/888-300/912) ${ }^{4}$. Habría sido al-Sarrāŷ quien convenció a este omeya para que se rebelara, abandonando Córdoba y dirigiéndose hacia el norte, a Faḥ al-Ballūt (Llano de los Pedroches) y la sierra de Almadén. Estas comarcas se caracterizaban por los asentamientos beréberes, especialmente de la tribu Nafza (Butr). Allí, al-Sarrāŷy e Ibn al-Qițt, quien se proclamó $M a h d \bar{i}$, incitaron a la población de las Marcas media e inferior a iniciar el yihäd contra los cristianos, atacando la ciudad de Zamora. Quienes respondieron, dicen las fuentes, fueron sobre todo los beréberes. Según el relato del ulema de origen beréber Mundir $b$. Sa'īd al-Ballūtị, Ibn al-Qițt se estableció primero durante un mes entre sus parientes de la tribu de Kazna (Nafza), pero sin revelar sus propósitos. Marchó luego a Nafza, entre los Banū Rāšid, junto al Guadiana, donde permaneció varios meses y donde dio a conocer sus proyectos. Indica Guichard que esos Banū Rāšid pueden ser

1 Quiero agradecer a Luis Molina sus útiles comentarios.

2 V. Fierro, M. I., La heterodoxia en al-Andalus durante el periodo omeya, Madrid, 1987, 93-4 y 118-20. Para la época califal v. ibid., 142-5, 149-155 y 157-9.

3 V. Walker, P., «The identity of one of the Ismaili $d \bar{a}$ ' $i s$ sent by the Fatimids to Ibn Hafșūn", Al-Qanțara XXI (2000), 387-8.

$\dot{4}$ Para lo que sigue sobre este personaje v. Guichard, P., Al-Andalus. Estructura antropológica de una sociedad islámica en Occidente, Barcelona, 1976, 385-391; Fierro, Heterodoxia, 106-111; Manzano, E., La frontera de al-Andalus en época de los omeyas, Madrid, 1991, 253-7.

Al-Qanțara XXV, 1 (2004) 239-243 
los señores beréberes de Mérida, pertenecientes a la tribu Maṣmūda (Barānis), conocidos también como Banū Tāŷît ${ }^{5}$. Si Nafza se entiende como una localidad, se la identifica generalmente con el actual despoblado de Vascos, situado en la margen izquierda del Tajo, a poca distancia de Puente del Arzobispo ${ }^{6}$, pero más probablemente «todo un territorio comprendido entre las cuencas del Tajo y el Guadiana era conocido con el nombre de la tribu beréber que señoreaba este territorio» ${ }^{7}$.

Señala Guichard que «la propaganda político-religiosa del supuesto Mahdī obtuvo muy pronto un gran éxito en las regiones en que se divulgó, esto es, en el $\hat{Y} a w f$ (que parece haber designado en aquel tiempo toda la cuenca media del Guadiana), el Garb (es decir, el Sudoeste de al-Andalus), así como en las regiones más orientales de Toledo y de Talavera, llegando incluso a Guadalajara y a Santaver». Además de grupos tribales Nafza y Mașmūda, tenemos noticia también de la presencia de Miknāsa (Butr) entre los seguidores de Ibn al-Qitṭ.

Quienes se han ocupado del asunto de Ibn al-Qitt han puesto de relieve su similitud con la experiencia fatimí. Un misionero isma 'ilí oriental, el $d \bar{a}^{c} \hat{\imath}$ Abū 'Abd Allāh, se estableció entre los beréberes Kutāma de Ifrīqiya y entre ellos hizo propaganda a favor de la dinastía fatimí, convirtiéndolos en un ejército que logró derrotar a los Aglabíes y llevar al poder al primer califa de esa dinastía, quien asumió el título de al-Mahdī en el año 296/909. Las ventajas que ofrecían los Kutāma (aunque otros grupos bereberes las habrían podido ofrecer igualmente) en Ifrīqiya para quienes quisieran promover una rebelión contra el poder establecido son puestas de manifiesto en un texto extraordinario en muchos sentidos y que reproduzco aquí en la traducción de H. Halm / M. Bonner. En él, se narra el encuentro entre el $d \bar{a}^{6} \grave{l}$ y los beréberes Kutāma y se cuenta cómo

In the course of his conversations Abū 'Abdallāh kept on asking them about their country and the conditions in which their people lived. And from what they told him he could see that the region was favorable to his plans. He asked them, among other things, «How do you obey the supreme authority (sultān) and how does it rule over you?» They replied, «Our obedience and the [sultān's] rule are limited to our saying: There is a sultāan». «How far away from you is it?» «A journey of ten days.» «And are there fortified cities nearby?» They said that there were... He asked them whether the rulers of North Africa... had any governors there, and they said they did not. There were individual men who ruled alone over the various cities, but these had nothing to do with the rulers, beyond having the prayer said for them in the pulpits; they were thus disobedient in their obedience to the government.

5 V. sobre esta familia: de Felipe, H., Identidad y onomástica de los beréberes de al-Andalus, Madrid, 1997, 228-30 (se les identifica como Banū Tāŷît).

6 V. de Felipe, Identidad, 319-20.

7 Manzano, Frontera, 182. 
«Then do you owe them obedience?» «Not at all; they rather fawn on those of us who go to them, for we are superior to them in strength.» «Then who rules over you?» «Each of us has power over himself! We have great men in every tribe, and there are people among us who occupy themselves a little with scholarship, and there are also teachers whom we ask for advice in religious matters, and whom we summon to act as judges in our disputes....» «And with all this, no authority has any leverage against you?» They said no, there was none. «How large is your country?» «Five days's journey in length and three in width.» "Then you are unified among yourselves?» «No, we fight one another, and after someone has gained the victory, we join together again. Many of us live in peace with one group, while fighting another; this is our custom.» «But if a stranger tries to force his way in among you, do you hold together?» «No one has ever tried that!» «And why not?» «Because we are so many, and our country is so impassable.» «How many are you, then?» «No one, neither from among us, nor so far as we know from outside, has ever counted us.» «Do you have horses and weapons?» «They are our most important possession, and all our pride; we collect these things because we need them for our fights with one another» ${ }^{8}$.

La actividad del $d \bar{a}^{\prime} \bar{l}$ fatimí tuvo lugar entre los años 893-909 d.C., siendo pues anterior a la de Abū 'Alī al-Sarrāŷ, con la que coincide parcialmente. Pero si al-Sarrāŷ era un agente fatimí (¿tal vez dependiente del $d \bar{a}^{\prime} \bar{i}$ que actuaba en el Norte de África?), sorprende que promoviese la rebelión de un Mahdī que no tenía ascendencia fatimí (es decir, que no era descendiente de la hija del Profeta, Fātima, a través de su matrimonio con 'Alī b. Abī Tālib) ${ }^{9}$, a no ser que lo que pretendiese fuese suscitar disturbios que agudizasen la crisis del emirato omeya y contribuyesen a su caída, para desvelar luego la verdadera identidad del Mahdi, es decir, proclamando al califa fatimí.

Si esto fue así, quiero plantear la posibilidad de que Abū 'Alī al-Sarrāŷ buscase el apoyo de los Kutāma establecidos en la Península Ibérica, entre los que podía valerse del apoyo que sus contríbulos norteafricanos estaban prestando a la causa del Mahdi. No sería ésta la primera vez que los acontecimientos político-religiosos de la otra orilla del Estrecho tuviesen repercusiones en al-Andalus: recuérdese el caso de la revuelta beréber del año 121/739.

Los Kutāma no eran una de las tribus beréberes más numerosas de entre las que se habían asentado en la Península Ibérica. Su presencia está localizada en tres áreas ${ }^{10}$ : Alpuente ${ }^{11}$, la cora de Elvira y Saktān (en Toledo).

${ }^{8}$ Halm, H., The empire of the Mahdi. The Rise of the Fatimids, translated from the German by Michael Bonner, Leiden: Brill, 1996, 40-1.

9 V. al respecto Fierro, M., "On al-fățimī and al-fățimiyyūn», Jerusalem Studies in Arabic and Islam 20 (1996), 130-161.

${ }^{10}$ Hay una referencia a una familia de origen Kutāma asentada en Córdoba: v. De Felipe, Identidad, 186, 327.

${ }_{11}$ De Felipe, Identidad, 284, 294. Este asentamiento no tiene relevancia para lo que discutimos en esta ocasión, ya que las referencias a él aparecen en el s. V/XI. 
Por lo que se refiere a la zona de Elvira, dos cabecillas Kutāma, conocidos como los Banū Muhallab, se adueñaron de dos fortalezas en la zona, rebelándose contra el emir 'Abd Allāh, si bien luego volvieron a la obediencia, enfrentándose entonces a otros rebeldes, como Ibn Hafșūn. Volvieron a rebelarse nuevamente en época de 'Abd al-Rahmmān III, cuando dejamos de tener noticia de ellos ${ }^{12}$. Es de suponer que esos cabecillas derivasen su poder de una base tribal, pero las fuentes nada dicen al respecto.

Por lo que se refiere a Saktān, se trataba de un enclave de asentamiento beréber situado en las cercanías de Talavera ${ }^{13}$, identificado recientemente con la actual población de Escalona, en la provincia de Toledo, situada a orillas del río Alberche ${ }^{14}$. Manzano, sin embargo, piensa que esta identificación no es segura: «Las indicaciones del Muqtabis $V$ apuntan a que Saktān se encontraba cerca de una zona montañosa por la que transcurría una ruta que permitía dirigirse hacia Yilliqiyya: dos embajadas cristianas regresaron hacia el norte pasando por Saktān, mientras que un ataque realizado contra este bastión por un Bermudo Núñez, conde de Salamanca en el año 942/330H., fue repelido en el desfiladero de al-Masāŷid, el cual debe ser identificado con alguno de los puertos que franquean el Sistema Central entre el Puerto de Arrebatacapas y el Puerto de Tornavacas» ${ }^{15}$.

Los beréberes asentados en Saktān eran Kutāma. Lo sabemos de manera incidental. En efecto, narra Ibn Hayyān que durante la expedición llevada a cabo por Ordoño II en tierras extremeñas (año 303/915), atacó el rey cristiano la fortaleza de Alanje en la que «habitaban por entonces los Barānis de Kutāma que se habían visto obligados a abandonar la fortaleza de Saktān (tumma rahala bi- 'askari-hi ilà Qal'at al-Hanaš wa-kāna yaskunu-hā yawma 'id barānis Kutāma allad̄ina kānū qad aŷlaw ${ }^{16}$ min hịsn Saktān)» ${ }^{17}$. Co-

12 De Felipe, Identidad, 176-7, 303.

13 V. Manzano, Frontera, 178-9; de Felipe, Identidad, 331-2, quien señala que la primera referencia a los beréberes del lugar data del año 259/872-3, sin que se especifique su filiación tribal. V. también J. A. Santo, «Obras constructivas en al-Andalus durante el gobierno de 'Abd al-Raḥmān III», Qurțuba 1 (1996), 193-205, 204.

${ }_{14}$ V. Molénat, J. P., «L'organisation du territoire entre Cordillère Centrale et Sierra Morena du XIIème au XIVème siècle», en Génesis medieval del estado moderno: Castilla y Navarra (1250-1370), Valladolid, 1987, 69. Se corrige así la anterior identificación propuesta por Makki, M.A. en sus notas a la edición del Muqtabis de Ibn Ḥayyān.

${ }_{15}$ Manzano, Frontera, 179 y $368-9$ y el mapa en las pp. $420-1$.

${ }^{16} \mathrm{El}$ ms. unicum consigna esta vocalización (debo esta información a L. Molina).

17 Ibn Hayyān, al-Muqtabas V, ed. P. Chalmeta, F. Corriente y M. Subh, Madrid, 1979; trad. Viguera, M. J. y Corriente, F., Zaragoza, 1981, 81 (donde aŷlaw se traduce por «habían evacuado»). Esta frase no implica desde luego que los Kutāma hayan sido los únicos pobladores de Saktān: v. al respecto: de Felipe, Identidad, 275, nota 11. La misma autora (p. 301) afirma que esos Kutāma estaban encabezados por un personaje llamado Ibn Rāšid (dato tomado del Muqtabis $V$ de Ibn Hayyān). Creo que ese Ibn Rāšid tiene que ser un miembro de los Banū Tãŷit. También afirma que la huida de Saktān aconteció en el año 303/915-6 «y fue motivada por una incursión de los cristianos del 
menta Manzano al respecto: «De esta noticia cabe deducir, por consiguiente, que al menos una parte de la población de Saktān había abandonado este emplazamiento durante la época de la fitna, aunque es casi innecesario decir que ignoramos en qué circunstancias se produjo este abandono» ${ }^{18}$.

La propuesta que hago es que dicho abandono debe ser puesto en relación con la rebelión de Ibn al-Qițt. Caben varias posibilidades de las que paso a indicar algunas.

Una posibilidad es que fueran los cristianos quienes hostigaran a los Kutāma tras la derrota infligida a Ibn al-Qitț y ello motivara la evacuación.

Otra posibilidad tiene relación con el hecho de que la localización de estos beréberes Kutāma en una fortaleza situada en una zona difícil de controlar por el poder central los hacía susceptibles de poder desarrollar entre ellos una actividad semejante a la llevada a cabo por el $d \bar{a}^{\prime} \hat{l} \mathrm{Abu}$ 'A Abd Allāh entre los Kutāma de Ifrìqiya. Sin embargo, había una clara diferencia numérica entre unos y otros. Si participaron en la rebelión beréber liderada por Ibn al-Qitt, su presencia no es registrada por las fuentes, que sí destacan la mayoritaria presencia de los beréberes Nafza. Pero éstos acabaron abandonando a Ibn al-Qitt, quien murió a manos de los cristianos. La defección de los Nafza pudo ponerlos a salvo de posibles represalias por parte de los omeyas por haber apoyado al Mahdī omeya. Pero si los Kutāma se mantuvieron fieles a él hasta el final, el gobierno central bien pudo considerar que seguían constituyendo una grave amenaza por su parentesco con los seguidores principales del califa fatimí, que los podía hacer susceptibles a nuevos episodios de rebelión, así como por su situación cercana a la frontera contra los cristianos. Hostigados tal vez por los omeyas, abandonaron Saktān y se dirigieron a Alanje, en la cora de Mérida, donde estaban establecidos los Mașmūda Banū Tāŷît (o Banū Rāšid), barānis como ellos y participantes también en la rebelión de Ibn al-Qitț. De hecho, en 316/928-9, un miembro de ese linaje, Mas'ūd b. Tâŷit, se hizo fuerte en el castillo de Alanje, aunque acabó siendo derrotado y trasladado a Córdoba.

Los Kutāma pudieron incluso ser deportados por los omeyas a una zona donde se pensase que se podía controlarlos mejor. Los Banū Tâŷît habían estado ya al servicio de los omeyas, y aunque habían sido receptivos a la propaganda de Ibn al-Qitt, pudieron luego volver a la obediencia. Esta posibilidad que acabo de plantear presenta la dificultad de que parece aventurado que los omeyas deportasen a los Kutāma a una zona donde podían ser controlados por sus contríbulos, pero también fortalecerse con ellos si los Banū Tâŷit decidían abandonar el partido omeya.

norte que destruyeron la mencionada fortaleza», pero el texto hayyāní deja claro que el abandono (forzoso) había ya tenido lugar.

18 Manzano, Frontera, 178. 